https://helda.helsinki.fi

\title{
1.5-generation immigrant adolescents' autonomy negotiations in transnational family contexts
}

\section{Turjanmaa, Kaisa Elina}

2017

Turjanmaa , K E , Jasinskaja-Lahti , I \& Alitolppa-Niitamo , A 2017 , ' 1.5-generation immigrant adolescents' autonomy negotiations in transnational family contexts ', Migration letters , vol. 14 , no. 1 , pp. $75-87$. https://doi.org/10.33182/ml.v14i1.317

http://hdl.handle.net/10138/308083

https://doi.org/10.33182/ml.v14i1.317

unspecified

acceptedVersion

Downloaded from Helda, University of Helsinki institutional repository.

This is an electronic reprint of the original article.

This reprint may differ from the original in pagination and typographic detail.

Please cite the original version. 


\title{
1.5-Generation Immigrant Adolescents' Autonomy Negotiations in Transnational Family Contexts
}

Elina Turjanmaa, Anne Alitolppa-Niitamo \& Inga Jasinskaja-Lahti

\begin{abstract}
This study explored how 1.5-generation immigrant adolescents negotiate their autonomy with their parents in a new cultural context. The studied adolescents are immigrants with African, Middle Eastern, Southern Asian, and EU/FSU background in Finland. The study is built on the ecological framework, which looks at development within the context of social systems. The study combines perspectives of cross-cultural psychology, acculturation research, and developmental psychology to explore autonomy in a transnational developmental context. The data consists of 80 semi-structured interviews with immigrant adolescents aged 13 to 18 . Our results suggest that adolescents' autonomy is negotiated within local family circumstances, while the transnational context becomes particularly crucial in the negotiation categories of peer relations and cultural continuity. Cultural differences in using different negotiation categories are discussed.
\end{abstract}

Keywords: Immigrant adolescents, transnational adolescents, 1.5 generation, intergenerational relations, autonomy 


\section{Acculturation and 1.5-Generation Transnational Immigrants}

Immigration is an increasingly complex worldwide phenomenon. In 2015, there were 76 million international migrants in Europe (United Nations, 2015). The number of immigrant families has increased rapidly in Finland, which has traditionally been an ethnically homogenous society. In Finland, the number of speakers of foreign languages is largest in Helsinki Metropolitan Area, where 13,5 per cent of the population spoke a language other than Finnish, Swedish or Sami as their mother tongue in 2015 (City of Helsinki, 2016).1 The City of Helsinki estimates that every fourth child aged $0-15$ years living in the area will be registered as a foreign language speaker in 2030 (ibid.).

Immigration and acculturation refer to the processes of cultural and psychological change that take place as a result of contact between cultural groups and their individual members (Redfield et al., 1936; Berry, 1997). These processes confuse a person's previous experience and knowledge, and lead to changes in social relations and self-image (Suárez-Orozco and Suárez-Orozco, 2001). Immigrant adolescents have typically been seen as more adaptive, flexible with norms and values, and quicker learners than their parents (Portes and Rumbaut, 2001). However, research also points to the particular dual transitional challenges of immigrant adolescents. Firstly, they encounter normative developmental tasks such as developing personal identity and, secondly, they confront acculturative tasks, such as learning a new language and habits (Alitolppa-Niitamo, 2004; Sam and Oppedal, 2003; Fuligni and Pedersen, 2002).

The target group of our study is adolescents who have migrated to Finland before or during their early teens (ages 7 to 14). This group represents the so called 1.5 generation, as opposed to the first 
or second generation (Portes and Rumbaut, 2001).2 The 1.5 generation forms a particularly transnational immigrant group. Their adolescence and development are largely affected by at least two cultures: the culture of their country of origin and that of the receiving country. Most importantly, 1.5-generation immigrants have first-hand experience of their original cultures and the country of emigration of their families. (Bartley and Spooney, 2008). These cultural and social ties pose demands in negotiating between the two cultures, particularly over issues of autonomy and identity (Suárez-Orozco and Suárez-Orozco, 2001; Phinney et al., 2006), and impact these migrants, creating multiple and hyphenated identities, and multiple notions of "home" (Alitolppa-Niitamo 2002; Verkuyten, 2005; Bartley and Spooney, 2008).

In our study, we combine cross-cultural perspectives and research on acculturation and transnationalism with the field of developmental psychology to study the autonomy negotiations of the 1.5 generation. In addition, we apply the analysis of multivoicedness (Aveling et al., 2015) in order to describe autonomy negotiations in a transnational context. According to Aveling and her colleagues (2015), conceptualizing the Self as multivoiced originates in the theoretical tradition of dialogism, where the Other is not in opposition to Self, but part of Self; further, the Self is reflected in relation to Others. For example, Bhatia (2002) has showed how immigrant and diasporic communities invoke the voices of host and home communities to position themselves within different social contexts.

The theoretical framework of our study is the ecological framework, which looks at development within the context of social systems. The ecological model of development regards interacting contexts of children (e.g., family, school, peers) as shaping their development (Bronfenbrenner,

2 First-generation immigrants refer to adult or nearly adult immigrants who will not be part of compulsory education and continuing socialization in the receiving society, whereas the second generation means those who were born to immigrant parents. In research, children who enter the new country before age of six (i.e., start their schooling career in the receiving society) are often regarded as being close to the definition of second-generation immigrants (Portes and Rumbaut, 2001; Bartley and Spooney, 2008). 
1979). In addition to immediate social settings, Bronfenbrenner's (1979) ecological systems model consists of the levels of community and cultural values. In our qualitative study, we focus on family, the group that forms one of the immediate social contexts of children's development (Onwuegbuzie et al., 2011). More specifically, our aim is to describe how the broader transnational family context of development, i.e., the context in which there coexists two, potentially competing, cultural understandings of autonomy, becomes salient in adolescents' autonomy negotiations. By using the analytic tool of multivoicedness (Aveling et al., 2015), we hope to specify how the transnational aspect of adolescents' lives shapes their autonomy.

\section{Intergenerational relations and adolescents' autonomy in different cultures}

Intergenerational relations are widely studied by family researchers from different fields (Steinberg, 2001). This research tends to focus on conflicts between adolescents and their parents, since intergenerational conflicts are considered to be detrimental for adolescents' acculturation processes (Kwak, 2003), as well as development and wellbeing in different cultural surroundings (Kağitçibaşi, 2005; Jensen and Dost-Gözkan, 2015). However, especially in Western psychology, intergenerational discrepancies are understood as part of normative development, in which the scope of autonomy is being negotiated, sometimes even in fiercely argumentative ways. Early adolescence is considered an important period for these negotiations of autonomy-related changes in the parent-child relationship (Steinberg, 2001; Kağitçibaşi, 2005).

Adolescents' autonomy can be conceptualized in several ways (for a review, see Noom et al., 2001). In line with recent psychological research, we understand autonomy as the 'self-governance of behavior in the context of supportive guidance, relational ties, and social commitments' (Smetana et al., 2004, 1418). In other words, adolescents' autonomy is defined in terms of interdependence and relatedness. Although we understand autonomy as agency (Kağitçibaşi, 2013), 
we acknowledge the social embeddedness and relational nature of human agency: our autonomy is relational in the sense that our social relationships and social determinants, such as race, class, gender, and ethnicity, are constantly contextualizing our agentic behavior (Christman, 2004).

Intergenerational family relations are affected differently across cultures and ethnocultural groups in terms of the onset and intensity of adolescents' desire for their own autonomy (Kwak, 2003). The traditional framework for understanding the nature of intergenerational relations across cultures is based on the continuum between collectivism and individualism (Tamis-LeMonda et al., 2008). Recent research, however, recognizes that adolescents from different cultures may simultaneously value both their autonomy and relatedness to their family (Kwak, 2003; Kağitçibaşi, 2007; MottiStefanidi et al., 2012).3

Intergenerational conflicts or potential conflict situations have been seen as a necessary context to study autonomy (Phinney et al., 2005), as they trigger opposing views on autonomy between adolescents and their parents. However, previous studies also suggest that immigrant adolescents do not necessarily experience greater intergenerational disagreements, but they do experience more conflict over the issue of autonomy (Kwak, 2003). Hence, we assume that autonomy negotiations also exist outside actual intergenerational conflicts.

The vast majority of previous psychological studies on adolescents' autonomy in immigrant families utilize quantitative approaches (e.g., Fuligni, 1998; Titzmann and Silbereisen, 2012). Studies on autonomy negotiation strategies have been built on the dichotomous understanding of autonomy and relatedness, which forces adolescents to choose their preferences within hypothetical conflict situations (e.g., Sugimura et al., 2009; Rasmi et al., 2014). Our study explores how

3 Similarly, parents from different ethnic groups may simultaneously value the independence and interdependence of their children, although the emphasis may vary across different ethnic groups (Suizzo, 2007; Tamis-LeMonda et al., 2008), and may change over time and contexts (Hui and Triandis, 1986; Kağitçibaşi, 2005). 
transnational 1.5-generation adolescents from different cultures negotiate their autonomy in real-life contexts.

\section{Data Collection and Methodology}

The interview data consisted of 80 semi-structured interviews of 1.5-generation immigrant adolescents (aged 13 to 18).4 All the participants were foreign-born. The group consisted of 45 boys and 35 girls, aged between 13-18 years (Table 1). They came from 26 schools, with the youngest in the 6 th grade and the oldest in senior high school. Most of the interviewees ( 86 per cent) attended junior high school. Their backgrounds were from 20 different countries and they represented 19 different mother tongues. The interviewees could be divided into four cultural groups according to the ethnic background of their families: African, Middle Eastern, Southern Asian and EU/FSU background. Adolescents' mean age of migration was 10 years. Most of them had arrived in Finland at the age of 7-12, which in the Finnish educational system corresponds with primary education, while 19 of them had migrated at the age of $13-14$, which corresponds with lower secondary education. In this study, all participants are considered to represent the 1.5 generation. All participants had lived in Finland for less than eight years.5

4 The data was collected in 2012 in Helsinki Metropolitan area in Finland. Interview questions addressed (1) migration, (2) family structure and background, (3) family relations, (4) social relations and support from family, peers and other sources, (5) schooling, and (6) future perspectives. Each theme was discussed with an emphasis on the changes, role and characteristics of intergenerational relations. The interviewees were recruited mainly from schools (via student counselors). Twelve of the participants were reached by snowball method. The interviews were held in schools with few exceptions, and lasted from 20 to 90 minutes (37 minutes being the average). Interviews were tape-recorded and transcribed. As the interviewers, we informed the participants that we were not connected to the school and that they could speak confidentially about anything. The interviews were held in Finnish, which was the mother language of the interviewers, but the second or the third language for the interviewees. The interviewees received two movie tickets as a compensation for their participation.

5 Participants' privacy and confidentiality have been protected at every stage of the research process. Children under 15 years old provided their parents' permission to participate in the study. The purpose of the study was introduced carefully to the interviewees, their families and the personnel in the schools. 
Table 1. Demographic Characteristics of the Sample.

\section{Adolescents $(n=80)$}

\begin{tabular}{ll}
\hline Gender & \\
Males & 45 \\
Females & 35 \\
Age & 12 \\
13 & 19 \\
14 & 22 \\
15 & 17 \\
16 & 7 \\
17 & 3 \\
18 & 29 \\
Country of origin & \\
Africa (Somalia, Gambia) & 18 \\
$\quad$ & \\
$\quad$ Middle East & \\
$\quad$ Iraq, Iran, Lebanon, Saudi Arabia, & \\
Turkey) & 9 \\
$\quad$ Southern Asia (Afghanistan, China, & \\
India, Thailand) & \\
$\quad$ EU/ FSU & 24 \\
Length of residence in Finland (years) & $M=4,7$ \\
Age of migration (years) & $M=10,4$ \\
\hline
\end{tabular}

Data was analyzed using qualitative content analysis (Hsieh and Shannon, 2005). We analyzed the entire contents of the interviews displaying autonomy negotiations within intergenerational relations. In other words, we looked for and categorized the accounts of decision-making in the family (e.g., the importance of family and other close relationships in decision-making and acting), and the interviewee's orientation to other groups, respect, duties, and obedience. After the main themes were identified, each was subjected to the analysis of multivoicedness: voices of the Self (internal I-positions), voices of Others (Inner-Other voices), and their interactions (Aveling et al., 2015). 


\section{Results}

In the analysis, we identified four main themes according to which autonomy negotiations were formulated: Family circumstances, parental authority, peer relations and cultural continuity. The content of negotiations in the categories of family circumstances and parental authority was similar in all four cultural groups. However, cultural differences occurred in the categories of peer relations and cultural continuity. The transnational context also became most evident in these two latter categories. Next, we will describe the categories shortly.

\section{Family circumstances}

The immediate living circumstances of a family, such as employment and livelihood, set an important frame for autonomy negotiations. In this category, adolescents stressed that their family's current circumstances demanded them to act in certain ways. Their interpretation of the obligation to take a certain role in a family was based more on material circumstances and less on culturally based models. For instance, adolescents were obligated to help their parents, especially in singleparent households. In some cases, adolescents' own desires for more autonomy were put aside because of the family's circumstances.

My mom wants me to be a role model, now that we don't have the role model of a father at home, to act as an example to my younger siblings. [...] I have to do all kinds of stuff at home. When mom's working, I have to put kids in bed and so on. Other kids of my age are out with their friends, like normal young people do. But I can't do that, so that's a little bit different (boy, 16 years, Africa).

Another example of situational factors framing adolescents' autonomy was a girl who had moved to Finland with her mother. Her mother was working in another town, often on weekends. The girl lived with her cousins, whom she did not like, and she felt lonely. School was difficult for her and 
she missed her mothers' support and presence. Taking care of school matters independently and relying on herself in decision-making was due to the family's difficult situation.

For sure she would like to be with me. But we had no choice. She [mother] doesn't want to sit at home [without work] (girl, 14 years, EU).

The category of family circumstances illustrates how the position of adolescents was often interpreted as being affected by situational factors and not by the culturally constructed values of adolescents or their parents. Adolescents talked particularly from the I-positions of the descendant or the sibling, emphasizing family relationships. The voice of parents was also recognizable, as adolescents pondered their responsibilities also through their eyes.

Transnational family circumstances framed autonomy negotiations particularly through cultural lenses and were, therefore, coded in the analysis under the category of cultural continuity. In the category of family circumstances, the transnational aspect of family life was indirectly present through the impact of absence of relatives and/or another parent on family life in Finland.

\section{Parental authority}

Autonomy negotiations included pondering about the parents' role in adolescents' choices and behavior. Adolescents referred to parents' role and authority in three different ways, each of which was applied by all four cultural groups.

Firstly, parents were presented as eligible authorities in relation to their children. Parents were presented as having a longer perspective and more knowledge, as well as always thinking the best of their children. This was the logic adolescents used when they negotiated the position of an authority for the benefit of their parents. Interestingly, parents were given the right to rule especially 
in situations where someone from outside the family was trying to influence adolescents' behavior. Not even new spouses of the parents were given the same right to intrude into adolescents' lives:

$$
\begin{aligned}
& \text { I don't like my stepfather taking part in our upbringing. Just because he's not our } \\
& \text { guardian, really. Sometimes he just tells us that we [children] should clean and that's } \\
& \text { just not actually his business. My mom rules (girl, } 14 \text { years, Russia). }
\end{aligned}
$$

Secondly, adolescents emphasized the equality of family members by stating that decisions in their families were made together. Presenting parents as equals to oneself was marking adolescents' autonomy in forming their opinions together with their parents:

Especially when it comes to my future or some big decisions. Actually I tell them basically just everything and they tell me if they think it's good or bad. I could say I've made some decisions on my own but they have contributed to them (girl, 18 years, FSU).

Thirdly, it became evident that the position of having authority may be in flux. Some interviewees considered that their parents' authority had declined. This was due to the contradictions and differences in opinions between parents and adolescents that had not been peacefully solved by negotiating. Even though adolescents with these views tried to find a balance between their own and parents' desires, they were not willing to respect at least some of the views and rules of their parents. This has led to actual disagreements at home. A strong preference to emphasize one's own autonomy was comparatively rare among participants. However, emphasizing the right for some autonomy and challenging parents' views occurred in all four cultural groups.

Of course I help with housework, we [family members] all have our own responsibilities. And then some other rules like homecoming hours. And I have done everything as my mom wishes, everything except that I don't respect her every word. 
That's the problem, for her. [...] I really don't know. If I don't feel like talking or I am angry, my mom just says 'why are you angry, everyone at home should be happy'. Can't I just be angry if I feel like it? But when I say that to her, that why am I not allowed to be angry, she just gets mad (girl, 17 years, Africa).

The transnational family context was not particularly salient in the category of parental authority. One participant described his father as taking an active part in the education of children and their daily life activities via skype, but, in general, the voices of parents living elsewhere were rarely expressed. Instead, a dialogue between adolescents' own voices and the voices of the parents with whom they lived was clearly distinguishable in the interview data.

\section{Peer relations}

Adolescents' reflected on their autonomy in comparison with other adolescents. Distinctions and comparisons were made in relation to Finnish adolescents, other immigrant adolescents and adolescents from one's own ethnic and/or cultural group. In some cases, the degree of autonomy of other adolescents was regarded as desirable and, at other times, as something to be despised.

Comparisons were often made in order to support adolescents' own level of autonomy and certain parenting practices at home. Finnish adolescents were often described as being disrespectful towards their parents. Another target of criticism was other families from one's own ethnic group:

Some parents, Somalis, their children may steal or do other bad stuff, and they [parents] just don't guide them enough. Even though that's the thing. That the whole family supports the child nevertheless. [...] Especially if you would go to Somalia and compare local kids to those kids who have been born in Finland, those born in Finland are so weird. They have more of a Finnish culture (boy, 16 years, Africa). 
In this case, the negatively framed new aspects of Somali parenting practices were at least partly equated to Finnish parenting practices. However, opposing views were expressed as well. In adolescents' comparisons, the behavior and autonomy of peers were also seen as desirable:

I think courage is good. Girls from our culture are taught to be quiet. They wouldn't run in the school hallway. I'm also like that. I wouldn't run in the corridors. [...] But I think it would be good to be active like that. Also, I don't like to keep company with boys that much. Some girls in our school are with boys all the time. But I can talk to them [boys] and I can sit with them (girl, 15 years, South Asia).

The reference groups varied in different contexts and were influenced by the size of ethnic community. Adolescents who were from immigrant groups that had rather big ethnic communities in Helsinki could make comparisons between adolescents from the same ethnic group and themselves. From the perspective of multivoicedness, there were several voices of Inner-Others in the talk of the adolescents: the voices of peers and one's own ethnic community in Finland and in the country of origin, and that of parents. The relatives and friends of a similar age in the country of origin were not directly used as a reference group for autonomy negotiations but rather represented as a generalized ethnic community with its values.

\section{Cultural continuity}

Lastly, cultural continuity was an important frame for autonomy negotiations. In this category, the transnational perspective becomes visible in adolescents' reasoning; their view was that a proper understanding of autonomy comes from their parents' culture. Hence, the category of cultural continuity entailed talk from I-positions representing one's own ethnocultural group (e.g., I-as-Iraqi, I-as-Thai). 
The interviewed adolescents expressed that they were consciously keeping their behavior in line with what they learned and internalized in their country of origin:

I cannot forget my former life. Even though it's new life now, new friends. But still. Nothing changes (girl, 16 years, Africa).

Negotiating autonomy in a cultural context was most common among adolescents of African and Middle Eastern background. This may be due to cultural and sociohistorical differences in the formation of interdependence of family and expected reciprocity between family members (Dilworth-Anderson et al., 2005). However, cultural reasoning in adolescents' autonomy negotiations must be interpreted carefully within the contexts of other social roles, race, and gender socialization. Social roles, such as son and daughter, can determine how individuals within a particular cultural group experience cultural expectations and obligations (ibid.). The interplay between cultural background and gender socialization became particularly salient in the accounts of boys with Southern Asian background, who worried most about their future autonomy and independency and expressed needs for family embeddedness in their decision-making also in the future. For them, this was related to their economic responsibilities towards the family since they believed that their parents and kin expected them to succeed in the new country so that they could support the whole family. In a few cases, interviewees' parents had voiced their goal of going back to the country of origin if their children could find their place and way to earn money in the new society. Hence, this kind of transnational migration strategy formed a frame for transnational family life and adolescents' autonomy negotiations.

\section{Discussion}

In this article, we have analyzed how 1.5-generation immigrant adolescents negotiate their autonomy with their parents in the context of the receiving country. The analysis revealed that the 
broader transnational context of the adolescents was relevant to their autonomy negotiations in indirect ways. The adolescents did not so much compare the degree of their autonomy directly with peers living in their countries of origin or in other diaspora countries. Instead, they compared their situation to peers, with the same or another ethnic background, who lived in Finland, and identified differences. In that sense they seemed to live literally 'here and now'. Also, parents that shared everyday life with their children were, unsurprisingly, important opponents, supporters, and guides within adolescents' autonomy negotiations. However, even though adolescents' autonomy negotiations were shaped by their local contexts, the transnational dimension was present via adolescents' use of multiple voices, such as those representing adolescents' ethnocultural identity and the wider ethnic community. Use of these multiple voices illustrates a 'dialogical' self that, in the migration context, involves also voices of race, culture, history and power that are tied with political and historical practices (Bhatia, 2002). The transnational context indirectly shaped family circumstances, but was more tangible in the categories of peer relations and cultural continuity, in which the various socio-culturally situated voices in adolescents' talk were present (Aveling et al., 2015).

The results illustrate the contextual nature of autonomy negotiations; they have parallels to a flexible and situational understanding of ethnic identity (Verkuyten, 2005) and represent the developmental context within interacting social spheres (Bronfenbrenner, 1979). Adolescents' autonomy negotiations with their parents manifest themselves in the interplay between adolescents and their parents, peers, and different cultural expectations. Our results suggest that transnational family life affects adolescents' autonomy development indirectly: through a generalized ethnic 
community6. Consequently, the results illustrate how the immediate social settings (family, peers), community, and cultural values shape adolescents’ development (Bronfenbrenner, 1979).

Also, our study emphasizes that autonomy negotiations do not necessarily involve actual intergenerational conflicts. Pondering, reasoning, and negotiating autonomy are constantly present within intergenerational relations, and work particularly to prevent conflicts. Kwak (2003) has noticed that members of immigrant families may be more motivated and adept to set disagreements among family members aside in order to enhance collaboration with each other in a new environment. The negotiation perspective to autonomy also brings forward the ambivalent nature of close relationships, containing both conflict and solidarity (see Bengtson et al., 2002).

The 'proper' amount of autonomy is consciously set in a canvas where the culture of the country of origin is recognized. In order to be able to draw more far-reaching conclusions, one should conduct a further study and compare whether the 1.5 generation is different in this respect from first and second generations. Also, the age phase of the adolescents who participated in the study formulates the results of the study. The crucial positions and contexts of autonomy negotiations may appear differently in late adolescence.

6 Likewise, expectations of a certain kind of parenting often come from other extended family members living in the country of origin or in other diaspora countries (Falicov, 2005). 


\section{References}

Alitolppa-Niitamo, A. (2002). "The generation in-between: Somali youth and schooling in metropolitan Helsinki”. Intercultural Education, 13 (3): 275-290.

Alitolppa-Niitamo, A. (2004). The icebreakers: Somali-speaking youth in the context of formal education in metropolitan Helsinki. Helsinki: Väestöliitto, Väestöntutkimuslaitos.

Aveling, E.-L., Gillespie, A. and Cornish, F. (2015). ”A qualitative method for analyzing multivoicedness". Qualitative Research, 15 (6): 670-687.

Bartley, A. and Spoonley, P. (2008). "Intergenerational transnationalism: 1.5 generation Asian migrants in New Zealand”. International Migration, 46 (4), 63-84.

Bengtson, V., Giarrusso, R., Mabry, J. B., \& Silverstein, M. (2002). Solidarity, conflict, and ambivalence: Complementary or competing perspectives on intergenerational relationships? Journal of Marriage and Family, 64(3), 568-576.

Berry, J. W. (1997). Immigration, acculturation, and adaptation. Applied Psychology: An International Review, 46 (1), 5-68.

Bhatia, S. (2002). “Acculturation, dialogical voices and the construction of the diasporic self". Theory \& Psychology, 12 (1), 55-77.

Bronfenbrenner, U. (1979). The ecology of human development: Experiments by nature and design. Cambridge, MA: Harvard University Press.

Christman, J. (2004). "Relational autonomy, liberal individualism, and the social constitution of selves”. Philosophical Studies, 117: 143-164. 
City of Helsinki (2016). Population with foreign language background in Helsinki 2015. Statistics 2016: 2. City of Helsinki Urban Facts.

Http://www.hel.fi/hel2/tietokeskus/julkaisut/pdf/16_01_15_Tilastoja_2_Hiekkavuo_Haapa maki_Ranto_Salorinne.pdf (retrieved 27 February 2016).

Dilworth-Anderson, P., Brummett, B., Goodwin, P., Williams, S., Williams, R. and Siegler, I. (2005). "Effect of race on cultural justifications for caregiving”. Journal of Gerontology, 60B (5): S257-S262.

Falicov, C. J. (2005). "Emotional transnationalism and family identities". Family Process, 44 (4): 399-406.

Fuligni, A. J. (1998). “Authority, autonomy, and parent-adolescent conflict and cohesion: A study of adolescents from Mexican, Chinese, Filipino, and European backgrounds”. Developmental Psychology, 34 (4), 782-792.

Fuligni, A. J. and Pedersen, S. (2002). "Family obligation and the transition to young adulthood". Developmental Psychology, 38 (5): 856-868.

Hsieh, H.-F. and Shannon, S. E. (2005). "Three approaches to qualitative content analysis". Qualitative Health Research, 15 (9): 1277-1288.

Hui, C. H. and Triandis, H. C. (1986). "Individualism-collectivism: A study of cross-cultural researchers". Journal of Cross-Cultural Psychology, 17 (2): 225-248.

Jensen, L. A. and Dost-Gözkan, A. (2015). “Adolescent-parent relations in Asian Indian and Salvadoran immigrant families: A cultural-developmental analysis of autonomy, authority, conflict, and cohesion”. Journal of Research on Adolescence, 25 (2): 340-351. 
Kağitçibaşi, C. (2005). “Autonomy and relatedness in cultural context: Implications for self and family". Journal of Cross-Cultural Psychology, 36 (4): 403-422.

Kağitçibaşi, C. (2007). Families, self and human development across cultures: Theory and applications. Mahwah, NJ: Lawrence Erlbaum.

Kağitçibaşi, C. (2013). “Adolescent autonomy-relatedness and the family in cultural context: What is optimal?". Journal of Adolescent Research, 23 (2): 223-235.

Kwak, K. (2003). “Adolescents and their parents: A review of intergenerational family relations for immigrant and non-immigrant families". Human Development, 46: 115-136.

Motti-Stefanidi, F., Berry, J., Chryssochoou X., Sam D. and Phinney, J. (2012). “Positive immigrant youth adaptation in context: developmental, acculturation, and sociopsychological perspectives”. In: A. Masten, K. Liebkind and D. Hernandez (eds.) Realizing the potential of immigrant youth (pp. 117-158). Cambridge: Cambridge University Press.

Noom, M., Dekovic, M. and Meeus, W. (2001). "Conceptual analysis and measurement of adolescent autonomy”. Journal of Youth and Adolescence, 30 (5): 577-595.

Onwuegbuzie, A. J., Collins, K. M. T. and Frels, R. K. (2013). Foreword: Using Bronfenbrenner's ecological systems theory to frame quantitative, qualitative, and mixed research. International Journal of Multiple Research Approaches, 7 (1): 2-8.

Phinney, J. S., Kim-Jo, T., Osorio, S. and Vilhjalmdottir, P. (2005). “Autonomy and relatedness in adolescent-parent disagreements: Ethnic and developmental factors”. Journal of Adolescent Research, 20 (8): 8-39.

Phinney, J. S., Berry, J. W., Sam, D. L. and Vedder, P. (2006). “Understanding immigrant youth: Conclusions and implications”. In: J. W. Berry, J. S. Phinney, D. L. Sam \& P. Vedder (eds.), 
Immigrant youth in cultural transition (pp. 211-254). Mahwah, New Jersey: Lawrence Erlbaum Associates.

Portes, A. and Rumbaut, R. (2001). Legacies: The story of the second generation. Berkley, CA: University of California Press.

Rasmi, S., Daly, T. M. and Chuang, S. S. (2014). "Intergenerational conflict management in immigrant Arab Canadian families". Journal of Cross-Cultural Psychology, 45 (7): $1124-1144$.

Redfield, R., Linton, R. and Herskovits, M. J. (1936). "Memorandum for the study of acculturation". American Anthropologist, 38 (1): 149-152.

Sam, D. L. and Oppedal, B. (2003). Acculturation as a developmental pathway. Online Readings in Psychology and Culture, 8 (1). http://dx.doi.org/10.9707/2307-0919.1072 (retrieved 7 September 2016).

Smetana, J., Campione-Barr, N. and Daddis, C. (2004). "Longitudinal development of family decision making: Defining healthy behavioral autonomy for middle-class African American adolescents". Child Development, 75 (5): 1418-1434.

Steinberg, L. (2001). "We know these things: Parent adolescent relationships in retrospect and prospect". Journal of Research on Adolescence, 11 (1): 1-19.

Suárez-Orozco, C. and Suárez-Orozco, M. (2001). Children of Immigration. Cambridge: Harvard University Press.

Sugimura, K., Yamazaki, M., Phinney, J. S. and Takeo, K. (2009). “Compliance, negotiation, and self-assertion in Japanese adolescents' disagreements with parents". International Journal of Behavioral Development, 33 (1): 77-87. 
Suizzo, A.-M. (2007). "Parents' goals and values for children: Dimensions of independence and interdependence across four U.S. ethnic groups". Journal of Cross-Cultural Psychology, 38 (4): 506-530.

Tamis-LeMonda, C. S., Way, N., Hughes, D., Yoshikawa, H., Kahana Kalman, R. and Niwa, E. Y. (2008). 'Parents' goals for children: The dynamic coexistence of individualism and collectivism in cultures and individuals”. Social Development, 17 (1): 183-208.

Titzmann, P. and Silbereisen, R. (2012). “Acculturation or development? Autonomy expectations among ethnic German immigrant adolescents and their native German age-mates”. Child Development, 83 (5): 1640-1654.

United Nations (2015). International migration 2015.

Http://www.un.org/en/development/desa/population/migration/publications/wallchart/docs/ MigrationWallChart2015.pdf (retrieved 27 February 2016).

Verkuyten, M. (2005). The social psychology of ethnic identity. Hove, UK: New York: Psychology Press. 